Revue d'histoire de l'Amérique française

REYUE D.HISTOIRE DE L'AMÉRIQUE FRANÇAISE

\title{
PERRON, Normand et Serge GAUTHIER, Histoire de Charlevoix (Sainte-Foy, Institut québécois de recherche sur la culture, coll. "Les régions du Québec ", n 14, 2000), 396 p.
}

\section{Chantal Collard}

Volume 56, numéro 3, hiver 2003

URI : https://id.erudit.org/iderudit/007631ar

DOI : https://doi.org/10.7202/007631ar

Aller au sommaire du numéro

Éditeur(s)

Institut d'histoire de l'Amérique française

ISSN

0035-2357 (imprimé)

1492-1383 (numérique)

Découvrir la revue

Citer ce compte rendu

Collard, C. (2003). Compte rendu de [PERRON, Normand et Serge GAUTHIER, Histoire de Charlevoix (Sainte-Foy, Institut québécois de recherche sur la culture, coll. « Les régions du Québec ", $\mathrm{n}^{0} 14,2000$ ), 396 p.] Revue d'histoire de l'Amérique française, 56(3), 420-422. https://doi.org/10.7202/007631ar d'utilisation que vous pouvez consulter en ligne. 
Quoi qu'il en soit, dans une édition critique, l'essentiel, ce sont les textes. Surtout si on la compare à l'affligeante présentation matérielle de la précédente édition, celle de Falardeau, celle-ci procure un vrai plaisir de lecture.

FERNANDE ROY

Département d'histoire

Université du Québec à Montréal

PERRON, Normand et Serge GAUTHIER, Histoire de Charlevoix (Sainte-Foy, Institut québécois de recherche sur la culture, coll. «Les régions du Québec», n 14, 2000), 396 p.

Le but de la collection dans laquelle s'insère ce travail est de présenter, pour le grand public, une vue d'ensemble de chacune des régions du Québec, depuis les origines amérindiennes ou inuit jusqu’à nos jours.

Ce livre vient combler un vide sérieux dans les études sur Charlevoix, et offre une synthèse historique de la région fort utile pour les chercheurs, comme pour la population locale, qui d'ailleurs a financièrement contribué (avec l'Institut national de la recherche scientifique, centre Culture et Société) à ce travail d'envergure. Il est bien documenté et argumenté, abondamment illustré et d'une lecture facile.

L'ouvrage comprend neuf chapitres : quatre sont écrits par Serge Gauthier (sur le début de l'occupation humaine, les différents regards portés sur Charlevoix et la culture locale) et cinq par Normand Perron (sur le milieu physique, la fondation des villages de la côte, celle des villages de l'arrière-pays et la période historique récente).

Les sources utilisées sont quantitatives - données démographiques, recensements, statistiques gouvernementales, ou qualitatives - textes de découvreurs, de voyageurs, de chroniqueurs et de villégiateurs. Les auteurs ont porté une attention particulière à la documentation locale, provenant des archives publiques — paroissiales et religieuses, municipales, scolaires, judiciaires - ou privées - entreprises, voire particuliers, privilégiant ainsi un regard de l’intérieur. Cependant ils ne nous présentent pas une vue «nombriliste» de la région, car ils sont aussi allés chercher les grandes forces externes, les visées des dirigeants, les compétitions et luttes économiques et politiques entre régions - lorsqu'il s'agit, par exemple, de tracer une route ou d'implanter une industrie — pour expliquer l'histoire et l'évolution de Charlevoix.

Le parti pris théorique de l'ouvrage est que la culture est le produit de la société et de l'économie. Les auteurs portent en conséquence une 
grande attention au cadre géographique du pays, à l'évolution du peuplement, aux principales composantes de l'économie - agriculture, forêt, cabotage - liées aux activités traditionnelles ainsi qu'aux tentatives de développement industriel ou touristique.

Pour la majorité des Québécois, pour un grand nombre de Canadiens et pour certaines familles aisées des États-Unis, la région de Charlevoix évoque sans conteste une entité territoriale, un cadre culturel facilement identifiables. Outre sa vocation de lieu de villégiature aux paysages splendides, elle est aussi perçue comme la terre d'origine de nombreuses familles québécoises qui ont essaimé partout au Québec. La population de Charlevoix est très homogène; elle est presque totalement francophone et en grande majorité de religion catholique. Les résidants de souche écossaise, irlandaise ou allemande, entre autres, ont adopté la langue française et leurs descendants ont fait de même. En fait, la présence d'anglophones ou de protestants dans la région aurait été plutôt limitée sans l'apport des séjours estivaux des villégiateurs ontariens ou américains dans Charlevoix Est. L’analyse matérialiste de Serge Gauthier et Normand Perron fait ressortir au fil des pages un visage de Charlevoix moins glorieux que celui présenté ci-haut, celui d'une petite région, peuplée seulement sur une mince section de son territoire et dont l'importance stratégique et économique est réduite.

Plutôt que de constituer une région naturelle bien unifiée, le milieu naturel de Charlevoix est diversifié. On y retrouve notamment trois zones étagées : basses de terres du littoral, plateau intermédiaire et hauts plateaux. L'histoire ajoutera comme le sait une autre division : celle entre Charlevoix Ouest et Charlevoix Est. Ce que découvrent les premiers voyageurs, c'est un espace habitable restreint et un terroir aux avantages naturels limités, ainsi qu'une présence amérindienne nomade et sporadique. L'image dominante qu'ils présentent du pays n'est pas celle des paysages pittoresques que nous connaissons de nos jours, mais plutôt celle d'un territoire dangereux et inhospitalier.

Aux $\mathrm{XVII}^{\mathrm{e}}$ et XVIII ${ }^{\mathrm{e}}$ siècles, le développement économique est marqué par des tentatives décevantes : échec de la goudronnerie royale et de l’industrie des mats dans le domaine forestier, improbables mines de fer, agriculture au potentiel limité. L’entité régionale n'existe pas encore; tout au plus faut-il parler d'îlots de peuplement aux confins des terres habitées de la NouvelleFrance, isolés par l'absence de chemins terrestres les reliant à Québec.

Les villages de la côte sont les premiers fondés. Cependant les auteurs notent qu'entre 1675 et 1849 Charlevoix reçoit peu d'immigrants et que le peuplement s'effectue surtout par la croissance démographique. Il en 
résultera une consanguinité élevée. Les villages de l'arrière-pays sont créés après les villages de la côte à partir de l'excédent démographique de ces derniers.

Au XIx ${ }^{\mathrm{e}}$ siècle, la poussée de colonisation vers le Saguenay, pourtant commencée par les entrepreneurs de Charlevoix, apporte peu au développement économique régional. Des discussions entre les habitants de l'Ouest et ceux de l'Est de la région sur l'emplacement des routes reliant Charlevoix au Saguenay font perdre un temps précieux. La construction d'un lien ferroviaire en direction du Saguenay-Lac-Saint-Jean avantagera finalement la ville de Québec au détriment de la région mère. Présente déjà depuis le milieu du $\mathrm{xIx}^{\mathrm{e}}$ siècle, au $\mathrm{xx}^{\mathrm{e}}$ siècle $c^{\prime}$ est l'industrie touristique qui prédomine.

Hier comme aujourd'hui l'équilibre démographique et économique de la région est précaire.

$\mathrm{Si}$ je porte un jugement très positif sur l'ensemble de cet ouvrage, je crois qu'à trop vouloir prendre le contrepoint d'études antérieures, ou de l'image que l'on a de Charlevoix, il y a certains éléments importants de la culture qui sont maltraités, comme la culture de la parenté si présente dans Charlevoix. Ainsi lorsque Normand Perron écrit (p. 118) que malgré la grande homogénéité démographique les interdits quant aux mariages consanguins sont respectés, en parlant des villages de la côte, les plus anciens, cela est faux. Cette culture de parenté est aussi plus que la seule consanguinité; c'est une culture de solidarité. De même si les études antérieures ont peut-être sous-estimé le contact avec l'extérieur, les auteurs eux le surestiment. En fait les mêmes contraintes d'une économie précaire se font sentir dans ce champ là aussi. Enfin, il n'y a pas que les touristes qui apprécient les paysages de Charlevoix; ces derniers constituent aussi un point d'attachement fort pour les habitants.

CHANTAL COLLARD Département de sociologie et d'anthropologie Université Concordia

POITRAS, Claire, La cité au bout du fil, le téléphone à Montréal de 1879 à 1930 (Montréal, Presses de l'Université de Montréal, 2000), 323 p.

Dans cette étude portant sur la mise en place du téléphone à Montréal de 1879 à 1930, Claire Poitras se fixe comme objectif de «mettre en lumière les mouvements de société associés à la percée du réseau téléphonique» (p. 17). Selon l'auteure, durant cette période, l’impact du réseau téléphonique 